\title{
Mind the Gap! Confronting the Challenges of Translational Communication Research in Entertainment-Education
}

Hua Wang and Arvind Singhal

The term "translational research" refers to research that makes it possible to translate abstract concepts into real-life applications (Romeroy \& Sanfilippo, 2015). In medicine, translational research often involves the process where "basic research" is conducted by scientists in the lab to test out new ideas; then it moves onto "clinical trials" with human subjects; and if successful, the result is disseminated through industry and institutions such as pharmacies and hospitals to change population-level practice (Rubio et al., 2010; Woolf, 2008). Translational research in the field of communication involves applying interpersonal and technology-mediated solutions to engage stakeholders from different sectors and disciplines,

\section{H. Wang $(\bowtie)$}

University at Buffalo, The State University of New York, Buffalo, NY, USA e-mail: hwang23@buffalo.edu

A. Singhal

The University of Texas at El Paso, El Paso, TX, USA

Inland University of Applied Sciences, Lillehammer, Norway

e-mail: asinghal@utep.edu

(C) The Author(s) 2021

L. B. Frank, P. Falzone (eds.), Entertainment-Education Behind the

Scenes, https://doi.org/10.1007/978-3-030-63614-2_14 
implementing innovative methods and measures, and contributing to effective and sustainable efforts to improve people's quality of life (Kreps, 2020). The focus of this chapter, the entertainment-education (EE) strategy, represents an intriguing area of translational communication research with wide-ranging implications for theory and practice of health promotion and social change.

Our pathway and purpose for this chapter are two-fold: (1) By chronicling the historical and recent developments of EE, we emphasize why EE researchers should not be shy of stepping out of their ivory towers to actively engage the communities being served; and (2) by sharing our experience with two EE projects, one in the United States and the other in India, we illustrate the wide gap that exists between the ideals that typically guide research design and the realities in the field. In so doing, we distill the lessons learned about building deeply trusting and mutually beneficial partnerships between researchers and other stakeholders; and the advantage of adopting a multi-method "bicycle design" that is relatively low cost, high yield, steadfast, and yet nimble enough to swiftly adapt to project needs.

\section{Entertainment-Education as an Evolving Field}

In the past five decades, EE has evolved from being a creative fieldcentered approach aimed at addressing real-world problems to an established field of scholarship and praxis in social and behavioral change communication (SBCC) (SBCC Summit Report, 2018; Singhal, Wang, \& Rogers, 2013; Storey \& Sood, 2013).

\section{History of the Rise of Entertainment-Education}

EE gained currency by accident when a telenovela, Simplemente Maria (Simply María), took Peru by storm from 1969 to 1971 and subsequently swept across Central and South America (Singhal, Obregon, \& Rogers, 1994). Its story revolved around the travails and triumphs of its protagonist, Maria, a rural-urban migrant who worked as a maid during the day and enrolled in adult literacy classes at night. She also developed seamstress skills using a Singer sewing machine and, as the plot twisted and turned, became a renowned fashion designer. Simplemente Maria attracted record-breaking ratings in Peru- on average about $85 \%$. Surprisingly, the sale of Singer sewing machines skyrocketed as did enrollments in adult 
literacy classes. Such phenomena occurred not just in Peru but in all countries of Central and South America where the telenovela was broadcast. What was supposed to be just another entertaining television serial on a commercial network turned out to be something with much wider social implications (Singhal \& Rogers, 1999).

The Simplemente Maria fever sparked a moment of epiphany for Mexican television writer-producer-director, Miguel Sabido. Struck by the unprecedented audience success of Simplemente Maria, Sabido was convinced that mass-mediated dramatic storytelling had the potential to shape public discourses on important social issues and even change audience behavior. Sabido studied human communication theories in many disciplines: Eric Bentley's (1967) dramatic theory, Carl Jung's (1953, 1970) theory of archetypes, Paul MacLean's (1973) triune brain theory, and Albert Bandura's $(1977,1986$ ) social learning/cognitive theory. Backed by an interdisciplinary conceptual foundation, Sabido actively began experimenting with social use of melodramatic serials on television. Through trials, evaluation research, and constant incorporation of learnings, he produced seven EE telenovelas between 1975 and 1982 to promote issues like adult literacy, family planning, and gender equality (Sabido, 2004). There was evidence to suggest that Sabido's telenovelas significantly boosted enrollments in adult literacy classes and led to increased adoption of condoms, pills, and other reproductive health services (Poindexter, 2004; Singhal \& Rogers, 1999). And the method he developed to produce EE serial dramas began to be called the Sabido methodology.

Over the next couple of decades, EE and the Sabido methodology snowballed globally, inspiring the development of television soap operas such as Hum Log (We People) in India (Singhal \& Rogers, 1988) and radio soap operas such as Twende Na Wakati (Let's Go with the Times) in Tanzania (Vaughan, Rogers, Singhal, \& Swalehe, 2000). The Sabido methodology was adopted and adapted far and wide in countries of Latin America, Asia, and Africa, championed mainly by the international nonprofit, Population Communication International, and Johns Hopkins University's Center for Communication Programs (Singhal \& Rogers, 1999). While early EE practice centered around serving communities in developing countries with reproductive health and HIV prevention messages (Singhal, Cody, Rogers, \& Sabido, 2004), EE now tackles a wide range of complex social issues around the world (Sood, Riley, \& Alarcon, 2017), such as domestic violence (Yue, Wang, \& Singhal, 2019), 
post-genocide group prejudice (Paluck, 2009), cancer prevention (Murphy et al., 2015), organ donation (Morgan, Movius, \& Cody, 2009), and environmental sustainability (Reinermann, Lubjuhn, Bouman, \& Singhal, 2014). With Sabido's trials and experiments with EE drama serials in Mexico, and also their global adoption and adaptation, EE represents a worthy case of translational communication research.

\section{Keeping with the Times: Changing Definition of Entertainment-Education}

In its early years, the primary spread of EE occurred through entertainment genres in radio and television. EE practitioners mainly worked with government agencies, non-governmental organizations, and creative professionals to develop prosocial drama serials. In that context, EE was defined as "the process of purposely designing and implementing a media message to both entertain and educate, in order to increase audience knowledge about an educational issue, create favorable attitudes, and change overt behavior" (Singhal \& Rogers, 1999, p. 9; also see Singhal et al., 2004, p. 5). The focus was to find the "sweet spot" that helped balance the entertaining and the educational elements in the story so the audience members would relate to the plots, fall in love with the characters, not feel they were being preached at, and could see new possibilities to enhance their lives.

At the turn of this century, with the internet becoming more accessible and popular, storytelling on web-based platforms with immersive environments rose rapidly. EE evolved with the capacities and possibilities that accompanied digital and interactive technologies. EE scholars also called for more theoretical development and diversity in EE research (Singhal \& Rogers, 2002). In 2009, we proposed a reformulated definition to emphasize that EE is "a theory-based communication strategy for purposefully embedding educational and social issues in the creation, production, processing, and dissemination process of an entertainment program, in order to achieve desired individual, community, institutional, and societal changes among the intended media user populations" (Wang \& Singhal, 2009 , pp. 272-273). This reformulation of the definition was necessary for at least three reasons: (1) EE programs expanded beyond radio and television dramatic serials to include music videos, cartoons, comic books, web series, and digital games; (2) EE initiatives spread from developing countries to include vulnerable audience groups in industrialized 
developing countries and media saturated markets; and (3) EE research broadened its conceptual and methodological scope (Singhal, 2013; Singhal, Cody, et al., 2004; Singhal, Wang, et al., 2013; Wang, Choi, Wu, \& DeMarle, 2018; Wang \& Singhal, 2016).

Through the lens of translational communication research, we now propose an updated definition of EE: Entertainment-education is a social and behavioral change communication (SBCC) strategy that leverages the power of storytelling in entertainment and wisdom from theories in different disciplines-with deliberate intention and collaborative efforts throughout the process of content production, program implementation, monitoring, and evaluation - to address critical issues in the real world and create enabling conditions for desirable and sustainable change across micro-, meso-, and macro-levels. Specifically, the following points deserve emphasis:

1. EE is an SBCC strategy that has been applied and embraced by global, national, and local change makers to serve the interests of underserved communities.

2. EE is characterized by deliberate intention and requires sustained creative efforts to seamlessly incorporate educational content with enabling features into the entertainment programming.

3. EE practice is situated in and derived from theories in human communication and other social science disciplines; it will continue to widen and deepen and become more nuanced with time.

4. EE purposely tackles real-life complex social problems and should engage key field-based stakeholders to foster trusting partnerships to enable desirable and sustainable change at the individual, community, institutional, and societal level.

In essence, $\mathrm{EE}$ is an instrumental and field-based practice, drawing upon theories from different disciplines (Wang \& Singhal, 2021). As diverse applications of EE occur across geographic regions, cultural contexts, and communication platforms, translational researchers need to recognize the following.

First, often scholars and practitioners loosely appropriate the term EE to refer to any entertainment program that happens to address a health or social issue. Despite the noble intentions of intervention designers and media producers, such programs are not EE. They are not created with a deep understanding of the theoretical foundation of EE, nor do they 
employ theory-based principles to interweave educational messaging with the dramatic storytelling, the audience/user experience, and/or the program evaluation.

Furthermore, as EE converges with experimental research in narrative persuasion, translational scholars should fiercely guard against methodological partisanship that view textbook lab experiments and inferential statistics as the gold standard. Much of the empirical research on narrative persuasion has been conducted with a uni-method approach and a sample bias characterized as "WEIRD," that is, Western, educated, industrialized, rich, and democratic (Eden et al., 2014, p. 514). These WEIRD biases become insidious when scholars fail to acknowledge the fundamental limitation of their research-the lack of ecological validity.

In contrast to lab experiments on narrative persuasion, EE is applied and translational by nature. Its very existence and evolution reside in its mission to purposely address the unmet needs of societal underdogs and tackle complex social problems in real-world settings. Recognizing this salient aspect of EE, that is, its purposive alignment between theory and practice, is vitally important.

\section{Gaps in Exemplary Entertainment-Education Projects}

We discuss two recent EE projects-East Los High in the United States and Main Kuch Bhi Kar Sakti Hoon (I, A Woman, Can Achieve Anything) in India-to illustrate the gaps that we pointed out in translational EE research.

\section{Testing Narrative Persuasion in East Los High}

One pioneering example of EE is the award-winning Hollywood web series East Los High (ELH), which ran on Hulu from June 2013 to December 2017. On the surface, ELH could be any popular Latinx teen drama set in a fictional high school in East Los Angeles. However, the producers purposely incorporated role modeling and credible resources about safe sex, family planning, and women's reproductive rights while addressing the social stigma and cultural barriers that young Latinx routinely face in the United States. ELH represents an effort of, by, and for the Latinx community (Wang \& Singhal, 2016; Wang, Singhal, et al., 2019). 
The story world of ELH comprised the flagship web series and multiple associated narrative elements that were strategically rolled out across nine other digital platforms: (1) extended ELH scenes to deepen character development and issue engagement; (2) The Siren, the school student newspaper that gave young people a voice to tell their own stories; (3) "Ask Paulie" - a platform that allowed Paulie, a funny and lovable character, to answer embarrassing questions about sexuality; (4) Ceci's vlogs which opened up a channel through her video blogs so that viewers could follow her teen pregnancy journey of dilemmas, options, and social support; (5) Tia Pepe's Mexican cooking recipes for tasty and healthy meals; (6) dance tutorials of the high school's Bomb Squad with signature moves as they prepare for the Big Five competition; (7) La Voz with Xavi to take pride in exploring cultural activities in East Los Angeles; (8) comic strips for trendy but important social topics; and (9) public service announcements delivered by ELH lead actors on behalf of partnering organizations such as StayTeen.org to inform and spur action among Latinx youth about health and social topics. These transmedia narrative experiences were further extended through resource links and widgets on the ELH website along with other audience engagement strategies on social media platforms such as Facebook and Twitter (Wang, Singhal, et al., 2019).

In order to assess the audience reach, engagement, and impact of $E L H$, our research team used a multi-method approach to capture the audience experience by conducting a viewer survey, an experiment differentiating various narrative experiences, digital analytics tracking, social network analyses, as well as participant observation and in-depth interviews with young Latinx couples at ELH watch parties. The program evaluation design, process, and results are well documented in terms of the broad geographic and sociodemographic reach among the ELH viewers, their enthusiastic response to the authentic stories and characters in $E L H$, and the potential of using narrative elements across digital platforms to meaningfully engage the audience and bring out positive change (Sachdev \& Singhal, 2015; Wang \& Singhal, 2016; Wang, Singhal, et al., 2019; Wang, Xu, Saxton, \& Singhal, 2019).

One finding on $E L H$ that we have not reported previously is a translational gap we observed while testing a theory of persuasion in the field. As background, in the early 2000s, as part of its theoretical development and diversification, EE research started to converge with the growing body of experimental research on narrative persuasion in media psychology (Wang \& Singhal, 2021). A number of theoretical concepts and models were 
introduced to explain and predict the ways in which media users process the information embedded in narratives and how it affects their perceptions. For example, "narrative transportation" focused on the mental process that explains why people can get "lost" in the world of stories, losing the sense of their immediate surroundings and feeling that they have traveled to different places and times (Green \& Brock, 2000). Another example was "identification with media characters," an imaginative process through which an audience member can put him/herself in the character's shoes to look at the world, consider the situation, and feel the emotions (Cohen, 2001).

Building on the theoretical development of narrative transportation and character identification, Slater (2002) argued that using stories in entertainment media for persuasion was fundamentally different from the dual (central and peripheral) information processing approach that Petty and Cacioppo (1986) called elaboration likelihood model (ELM). Instead, Slater and Rouner (2002) proposed an extended elaboration likelihood model (E-ELM) to help explain how EE stories persuade their intended audiences to change. They argued that factors like storyline appeal and quality of production would influence audience's narrative transportation and character identification, which in turn would affect their perceptions. Lab experiments with college students had shown considerable evidence on how narrative transportation and character identification led to storyconsistent attitudes, beliefs, and behavioral intentions (e.g., Bilandzic \& Kinnebrock, 2009; Green, Strange, \& Brock, 2002; Moyer-Gusé, 2008). Therefore, we wanted to see how well E-ELM applied to the ELH audience survey data.

We reported the sample characteristics and key measures in the ELH audience survey in Wang and Singhal (2016). For applied theory-testing of E-ELM, we used an advanced analytical technique called structural equational modeling. This technique allowed us to test multiple research hypotheses at the same time by examining each individual relationship while assessing how well the overall conceptual model fit the data with goodness-of-fit measures and modification indicators for model optimization. The final results after iterative model testing and modification are summarized in Fig. 14.1.

In each model, "behavioral intention" was tested as five separate outcome variables-use of condoms, emergency contraception, abortion health service recommendation, pregnancy testing, and pregnancy testing recommendation. Remarkably, all final models met the criteria for overall 


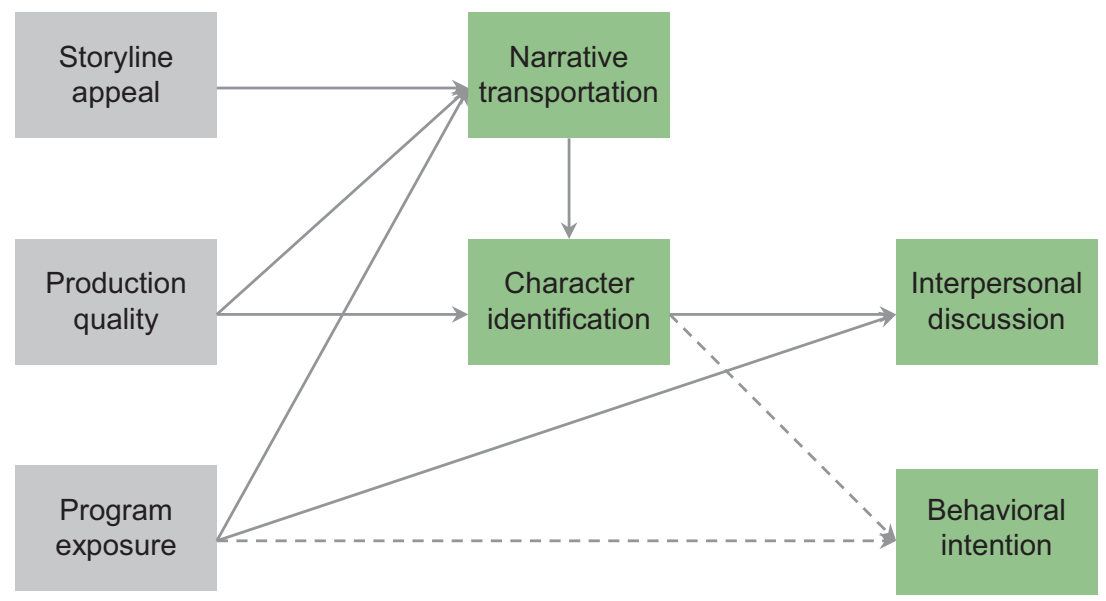

Fig. 14.1 Summary of East Los High viewer survey results of structural equation modeling

goodness-of-fit. However, not all individual hypotheses were supported. Solid arrows indicate the relationships that were consistently significant across all models. Dotted arrows indicate the relationships that were not significant in most models, therefore, not supported with sufficient empirical evidence.

More specifically, storyline appeal, production quality, and program exposure significantly predicted audience's narrative transportation into the $E L H$ story world. Production quality significantly also predicted audience's identification with the main characters in ELH. Program exposure also significantly predicted interpersonal discussion about ELH. Character identification appeared to be a full mediator between narrative transportation and interpersonal discussion. There was no support for a direct link from interpersonal discussion to behavioral intention during the model modification process. The links from program exposure and character identification to behavioral intention were not significant in most models with the exceptions of (1) a significant link from program exposure to behavioral intention regarding pregnancy testing recommendation and (2) a significant link from character identification to behavioral intention regarding pregnancy testing recommendation.

Simply, our ELH results point to the chasm that exists in doing labbased experiments and fieldwork. Published lab experiments conducted by 
media psychologists routinely show that exposure to narrative stimuli leads to statistically significant story-consistent attitudes, beliefs, and behavioral intentions. However, while our field-based survey data among the $E L H$ audience provided evidence of interpersonal discussion about the show, it did not indicate any direct or immediate effects on behavioral intentions. In essence, a sharp distinction existed between findings of a textbook clean research design in a well-controlled lab environment where data is collected right after respondents are exposed and what we found in a field survey with "real" respondents. While lab experiments valorize internal validity of findings, translational researchers will do well to test the ecological validity of results. That represents the key translational challenge in EE-that is, meeting the intended audience members where they are, systematically gathering information while minimizing biases, and triangulating findings through multi-method research designs.

\section{Nimbly Adapting Fieldwork in Main Kuch Bhi Kar Sakti Hoon}

We were also involved in the program evaluation of another exemplary EE initiative-Main Kuch Bhi Kar Sakti Hoon/MKBKSH (I, A Woman, Can Achieve Anything) in India. From March 2014 to September 2019, three seasons of MKBKSH comprising some 183 episodes were broadcast on Doordarshan, the Indian national television network, and hundreds of All India Radio stations as well as mobile and community networks to reach "media dark" rural areas (Wang \& Singhal, 2018). MKBKSH challenged entrenched regressive gender norms and advocated for women's empowerment through the positive role modeling of its protagonist, Dr. Sneha Mathur, who leaves behind a lucrative medical practice in Mumbai and returns to her home village to tackle multiple social ills—child marriage, sex selection in favor of male offspring, violence against women, and multiple manifestations of gender inequality.

$M K B K S H$ was the first EE intervention to use an interactive voice response system (IVRS) across all three seasons to invite and engage audience members at scale and in real time, allowing them to access and interact with curated $M K B K S H$ content, answer questions, and share personal opinions and actions inspired by MKBKSH (Wang \& Singhal, 2018). The IVRS represented a "voicebook" for millions of audience members, especially the rural, the socioeconomically poor, and the less privileged (Wang \& Singhal, 2018). Further, MKBKSH's story world was supplemented with a series of mini-documentaries titled "Reel to Real" documenting Dr. 
Sneha visiting real communities where the impact of $M K B K S H$ was profound. Two other miniseries, Kishor Ka Shor (The Voice of Youth) and Satya Ki Adalat (The Truth Court), were carved out of MKBKSH's television content, extending the storyline on $M K B K S H$ 's Facebook page and YouTube channel. In Season 3, a new transmedia extension was added by launching a chatbot called SnehAI (for Sneha AI) on the MKBKSH Facebook page via the Messenger app. This chatbot helped create a safe, non-judgmental, and private platform for India's youth to seek counseling services about sexual and reproductive health. Such services are virtually non-existent in India.

An interesting translational issue in program evaluation was observed in our MKBKSH field research. To understand the issue, a little background on EE program evaluations may be useful. Traditionally, EE program evaluations have relied heavily on audience reception surveys and have been criticized for participants' self-selection bias (Sherry, 1997). Over the past 25 years, scholars and practitioners have made extra efforts to secure resource and conduct assessments using more rigorous designs such as field experiments (e.g., Banerjee et al., 2019; Paluck, 2009; Vaughan et al., 2000). A recent meta-analysis on the use of EE narratives to promote safer sexual behaviors of youth from 1985 to 2017 only found 10 qualified publications using either a full or a quasi-experimental design in the field (Orozco-Olvera, Shen, \& Cluver, 2019). Thus, in our research design of $M K B K S H$ Season 3 program evaluation, we purposely included an experimental component with repeated measures in order to better understand whether the exposure to the storylines and the underlying educational themes made any difference among the audience as compared to those without any exposure. By visiting the same participants more than once, we hoped to track any individual-level changes over time.

We carefully selected the villages of Kanpur Dehat in India's most populous Uttar Pradesh state (population 200 million people with a total fertility rate of 3.1) as the site for the field experiment. The residents of Kanpur Dehat represent the characteristics of the MKBKSH intended audience with respect to both the theme of hygiene and sanitation and reproductive health and family planning. Working closely with our local NGO partner, Shramik Bharati, representative villages were identified to establish viewer versus non-viewer groups. We ensured that the nonviewing respondents were outside the broadcast area of the community radio station, which previously had broadcast the radio versions of $M K B K S H$ Seasons 1 and 2. 
Based on respondent selection guidelines provided by us with respect to gender and marital status, the field researchers of Centre for Media Studies (CMS), our data-collection partner, and our local NGO collaborator, Shramik Bharati, crafted a recruitment instrument to identify viewers and non-viewers at $\mathrm{Tl}$ baseline. This recruitment instrument took into account potential respondents' ownership of television sets, availability of the Doordarshan channel on which $M K B K S H$ was broadcast, their viewing habits with respect to television serials, and a reasonable availability of power supply, as power outages in rural India are common. So far, so good.

Further, Tl baseline data were collected in January 2019 prior to MKBKSH Season 3 launch on Doordarshan with 302 participants based on their gender and viewership status. Based on the preliminary results, a swift sampling adjustment was made in February 2019 to add 30 more participants to the viewer group who did not have a toilet at home to (1) balance out the participants' toilet ownership in the entire sample and (2) account for potential high attrition rate of $M K B K S H$ viewership at T2.

After the Tl baseline data collection, random manipulation checks carried out by CMS and Shramik Bharati gave us confidence that the nonviewers did not have any exposure to MKBKSH Season 3. However, alarmingly, the same checks showed that $M K B K S H$ viewership was very low even among our designated viewers (ranging from 10\% to 15\%). This meant that our small sample of viewers could doom our experimental design. On a war footing, we mobilized our local NGO partner Shramik Bharati to make another swift adjustment prior to T2 data collection, that is, after the broadcast of the first half of Season 3. Numerous individual and group viewing sessions (Fig. 14.2) were held with the designated viewers, so they were able to view at least five key sanitation episodes. These episodes focused on the sanitation plotline, the desired sanitation behaviors, including respect and compassion for sanitation workers, who are at the bottom of India's caste hierarchy. This swift field adjustment saved our experimental design —albeit temporarily.

Manipulation checks post T2 reconfirmed that low viewership to the second half of MKBKSH Season 3 continued, and so we had to further make a swift adaptation to our research design. Prior to T3, an 86-minute edited $M K B K S H$ Season 3 film containing the key reproductive health and family planning messages were shown to all designated viewers (Fig. 14.2), ensuring that each respondent had at least the 86-minute film as minimal exposure. And T4 was cut out due to resource contraints. 


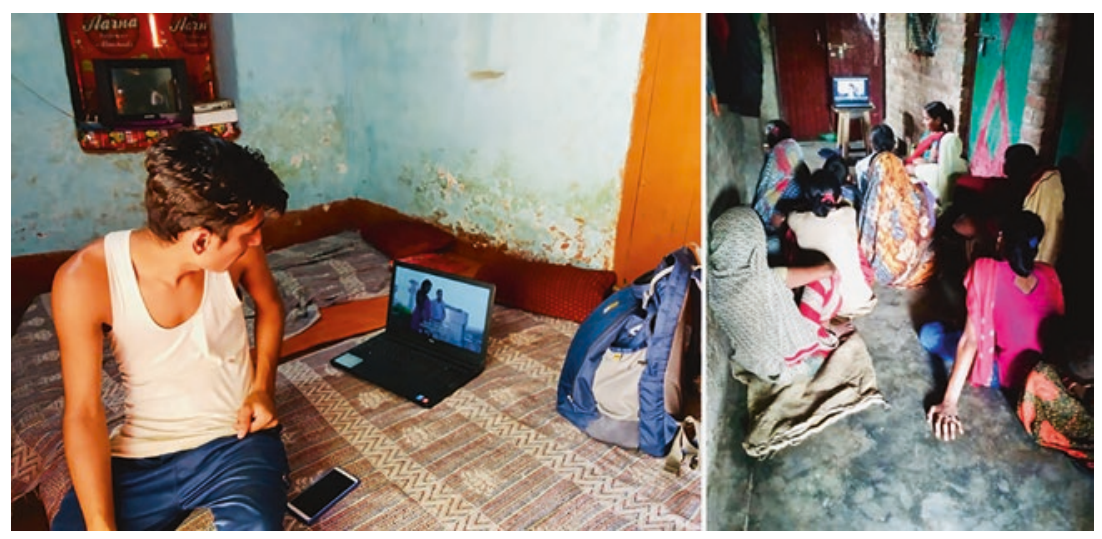

Fig. 14.2 MKBKSH Season 3 viewing sessions among villagers facilitated by Shramik Bharati

Thanks to our ability to leverage field-based partnerships and respond swiftly to field-based contingencies, a total of 514 residents in Kanpur Dehat participated in at least one, if not all three, in-person field surveys administered before, during, and after the broadcast of Season 3-in January, June, and November, 2019: T1 had 332 participants, T2 had 442 participants, and T3 had 421 participants. Tl served as the pretest for the first half of $M K B K S H$ Season 3 featuring the theme of sanitation and gender equality; T2 served as the posttest on sanitation-related assessments and pretest for the second half of $M K B K S H$ Season 3, featuring the theme of family planning and gender equality; T3 served as the follow-up on selected sanitation-related questions and posttest on family planningrelated assessments.

Our MKBKSH experience reinforces how difficult it is to reconcile a rigorous research design with shifting ground-based dynamics. If we had pursued a textbook clean experimental design and simply contracted our research partners to collect data, our $\mathrm{T} 1, \mathrm{~T} 2$, and $\mathrm{T} 3$ data would have been useless. A lot of time, effort, and resources would have gone down a meaningless drain. Instead, our research team spent a lot of time building strong and trusting partnerships between our data-collection agency (CMS) and local NGO partner, Shramik Bharati, weaving in several feedback and feedforward loops. Transparent open communication marked the research journey, problem-solving was a collaborative process. In its 
absence, we would have not have been able to discover the confounding factors in a timely manner, adjust our sampling strategy at baseline, or adapt to the unfolding realities in the villages to reduce the attrition rate over time in order to have sufficient quality data for meaningful program evaluation.

\section{Cross-pollination from $E L H$ to $M K B K S H$}

While we were able to implement a multi-method approach to assessing $E L H$, we missed a precious opportunity to evaluate its direct impact by a whisker. This costly lesson underscores how in the field, unlike a textbook lab experiment, things often fall through the cracks despite good planning and the noble intentions of partners. Remarkably, our NGO partner behind StayTeen.org worked closely with the $E L H$ production team to embed widgets on the $E L H$ webpage to enable motivated viewers to take actions, for example, search additional health information or seek a referral to a provider. For instance, a viewer could use a widget to type in their zip code to find local health clinics that provided a service featured in the show. While the entered zip codes were anonymous entries, they represented concrete health information-seeking behaviors directly resulting from the watching of ELH. Unfortunately, no such information was recorded. If the producers and writers had shared this possibility up front with the researchers and the NGO partners, a concerted effort could have been made to capture the anonymous entries of the zip codes that $E L H$ viewers used to look up for local resources, providing some of the best evidence in EE program evaluation.

Learning from this incredibly unfortunate missed opportunity, while working on $M K B K S H$, when our NGO partners obtained the approval from the Ministry of Health \& Family Welfare to provide their national toll-free helpline number to access information on sexual and reproductive health, we were able to work with the team to set up in the SnehAI chatbot analytics database to track the number of unique users and clicks on the helpline link and accumulate the evidence from thousands within a few short weeks. Our $E L H$ to $M K B K S H$ journey demonstrates that while translational "gaps" may emerge within the container of a project, the learnings gained in one project can inform the planning and execution of another that follows. 


\section{Lessons Learned and Best Practices}

EE represents an intriguing area of translational communication research for health promotion and social change. It holds the potential to interrogate theoretical concepts and models with creative practices in message design, intervention implementation, and program evaluation. Our experience with the two projects-ELH and $M K B K S H$ - points to the following lessons learned about translational communication research in EE:

Lesson \#1: Strive for internal and external validity and interrogate the strengths and weaknesses of lab experiments with fieldwork. A large gap exists between what is found in a well-controlled lab environment where data is collected right after respondents are exposed to a narrative persuasion intervention, and what is found in the applied theory-testing in the real world with a diverse set of respondents. Translational researchers should pay attention to the internal validity of lab-based findings but not be shy about stepping out of the ivory towers to constantly interrogate them in the field. Ultimately, translational scholars wish for their interventions to have high degrees of external and ecological validity.

Lesson \#2: Build deeply trusting and mutually beneficial partnerships among all key stakeholders. The effectiveness of EE program evaluation is highly dependent on open and trusting communication among the team of program evaluators and representatives of field agencies and local partners. Field immersion of program evaluators is essential for them to not treat the field as a neat textbook research lab, but to understand the daily rhythms of respondents, including their sowing and harvest seasons, local electoral calendars, and the like. Regular feedback and feedforward exercises, including manipulation checks and data monitoring, should be carefully built into the research process. Even experienced field research agencies must understand the value of making swift adjustments with respect to sampling strategies, including modifying, as needed, the nature of program intervention and treatment conditions to respond to fieldbased contingencies. Goodwill represents an important currency especially if budgets are limited, as they often are.

Lesson \#3. Adopt a multi-method approach with nimble costeffective "bicycle" research designs. This way, the findings can be triangulated from different types of input to provide a deeper understanding of what works and why, and what does not, and why. It is important for translational researchers of EE to not put all their eggs in one basket. Our 
research experience with $E L H$ and $M K B K S H$ suggests that when budgets are scarce, nimble cost-effective "bicycle" research designs may provide richer insights than an expensive uni-method "Cadillac" research design.

Lesson \#4: Privilege a multi-theoretical framework to EE scholarship and praxis. EE translational research should go beyond just audience reception and media effects studies grounded in the subfields of psychology (i.e., social psychology and media psychology). As our ELH and $M K B K S H$ research demonstrates EE can benefit tremendously from the knowledge and integration of resources in other related fields such as public health (e.g., promoting sexual and reproductive health among underserved population groups), sociology (e.g., using social network analysis to examine individual and organizational connections), information systems (e.g., digital tracking and IVRS for large-scale real-time audience engagement), and artificial intelligence (e.g., use of chatbots). The interdisciplinary nature of EE requires a multi-theoretical and multi-method approach so that the learnings and attributions can span the micro-mesomacro levels-from individual behavioral changes to community-, society-, and policy-level praxis.

\section{REFERENCES}

Bandura, A. (1977). Social learning theory. Prentice-Hall.

Bandura, A. (1986). Social foundations of thought and action: A social cognitive theory. Prentice-Hall.

Bentley, E. (1967). The life of drama. Atheneum.

Banerjee, A., La Ferrara, E., Orozco-Olvera, V. H. (2019, September). The entertaining way to behavioral change: Fighting HIV with MTV. Policy Research Working Paper 8998, Development Impact Evaluation Group, World Bank Group.

Bilandzic, H., \& Kinnebrock, S. (2009). Narrative experiences and effects of media stories: An introduction to the special issue. Communications, 34(4), 355-360. https://doi.org/10.1515/COMM.2009.022

Cohen, J. (2001). Defining identification: A theoretical look at the identification of audiences with media characters. Mass Communication and Society, 4, 245-264. https://doi.org/10.1207/S15327825MCS0403_01

Eden, A., Tamborini, R., Grizzard, M., Lewis, R., Weber, R., \& Prabhu, S. (2014). Repeated exposure to narrative entertainment and the salience of moral intuitions. Journal of Communication, 64, 501-520.

Green, M. C., \& Brock, T. C. (2000). The role of transportation in the persuasiveness of public narratives. Journal of Personality and Social Psychology, 79, 701-721. https://doi.org/10.1037/00223514.79.5.701 
Green, M. C., Strange, J. J., \& Brock, T. C. (Eds.). (2002). Narrative impact: Social and cognitive foundations. Erlbaum.

Jung, C. G. (1953). The collected works of C. G. Jung. Vol. 12. Psychology and alchemy. Bollingen Foundation Inc.

Jung, C. G. (1970). Archetypes and the collective unconscious. Editorial Paidos.

Kreps, G. L. (2020). Engaged communication scholarship: The challenge to translate communication research into practice. In H. D. O'Hair \& M. J. O'Hair (Eds.), The handbook of applied communication research: Volume I (pp. 93-102). John Wiley \& Sons.

MacLean, P. D. (1973). A triune concept of the brain and behavior, including psychology of memory, sleep, and dreaming. In V. A. Kral et al. (Eds.), Proceedings of the Ontario Mental Health Foundation meeting at Queen's University. University of Toronto Press.

Morgan, S. E., Movius, L., \& Cody, M. J. (2009). The power of narratives: The effect of entertainment television organ donation storylines on the attitudes, knowledge, and behaviors of donors and nondonors. Journal of Communication, $59,135-151$.

Moyer-Gusé, E. (2008). Toward a theory of entertainment persuasion: Explaining the persuasive effects of entertainment-education messages. Communication Theory, 18, 407-425. https://doi.org/10.1111/j.1468-2885.2008.00328.x

Murphy, S. T., Frank, L. B., Chatterjee, J. S., Moran, M. B., Zhao, N., de Herrera, P. A., et al. (2015). Comparing the relative efficacy of narrative vs. nonnarrative health messages in reducing health disparities using a randomized trial. American Journal of Public Health, 105, 2117-2123.

Orozco-Olvera, V., Shen, F., \& Cluver, L. (2019). The effectiveness of using entertainment education narratives to promote safer sexual behaviors of youth: A meta-analysis, 1985-2017. PLOS ONE, 14(2), e0209969.

Paluck, E. L. (2009). Reducing intergroup prejudice and conflict using the media: A field experiment in Rwanda. Journal of Personality and Social Psychology, 96, 574-587.

Petty, R. E., \& Cacioppo, J. T. (1986). Communication and persuasion: Central and peripheral routes to attitude change. Springer-Verlag.

Poindexter, D. O. (2004). A history of entertainment-education, 1958-2000. In A. Singhal, M. J. Cody, E. M. Rogers, \& M. Sabido (Eds.), Entertainmenteducation and social change: History, research, and practice (pp. 21-38). Erlbaum.

Reinermann, J.-L., Lubjuhn, S., Bouman, M., \& Singhal, A. (2014). Entertainmenteducation: Storytelling for the greater, greener good. International Journal of Sustainable Development, 17, 176-191.

Romeroy, C., \& Sanfilippo, F. (2015). How research can and should inform public policy. In S. A. Wartman (Ed.), The transformation of academic bealth centers: Meeting the challenges of healthcare's changing landscape (pp. 179-191). Elsevier. 
Rubio, D. M., Schoenbaum, E. E., Lee, L. S., Schteingart, D. E., Marantz, P. R., Anderson, K. E., et al. (2010). Defining translational research: Implications for training. Academic Medicine, 85, 470-475.

Sabido, M. (2004). The origins of entertainment-education. In A. Singhal, M. J. Cody, E. M. Rogers, \& M. Sabido (Eds.), Entertainment-education and social change: History, research, and practice (pp. 61-74). Erlbaum.

Sachdev, A., \& Singhal, A. (2015). Where international, intranational, and development communication converge: Effects of East Los High, an entertainmenteducation web series, on sexual decision-making of young Latino/a couples. The Journal of Development Communication, 26(2), 15-34.

SBCC Report. (2018). Shifting norms, changing behavior, amplifying voice that works: 2018 International SBCC Summit, featuring entertainment-education. Retrieved from https://sbccsummit.org/wp-content/uploads/2018/12/ SBCC_Summit2018_report.pdf

Sherry, J. L. (1997). Prosocial soap operas for development: A review of research and theory. Journal of International Communication, 4(2), 75-101.

Singhal, A. (2013). Fairy tales to digital games: The rising tide of entertainment education. Critical Arts, 27, 1-8. https://doi.org/10.1080/0256004 6.2013.766971

Singhal, A., \& Rogers, E. M. (1988). Television soap operas for development in India. Gazette, 41, 109-126.

Singhal, A., \& Rogers, E. M. (1999). Entertainment-education: A communication strategy for social change. Erlbaum.

Singhal, A., \& Rogers, E. M. (2002). A theoretical agenda for entertainmenteducation. Communication Theory, 12, 117-135.

Singhal, A., Cody, M. J., Rogers, E. M., \& Sabido, M. (2004). Entertainmenteducation and social change: History, research, and practice. Erlbaum.

Singhal, A., Obregon, R., \& Rogers, E. M. (1994). Reconstructing the story of "Simplemente Maria", the most popular telenovela in Latin America of all time. Gazette, 54, 1-15.

Singhal, A., Wang, H., \& Rogers, E. M. (2013). The rising tide of entertainmenteducation in communication campaigns. In R. Rice \& C. Atkin (Eds.), Public communication campaigns (pp. 321-333). Sage.

Slater, M. D. (2002). Involvement as goal-directed strategic processing: Extending the elaboration likelihood model. In J. P. Dillard \& M. Pfau (Eds.), The persuasion handbook: Developments in theory and practice (pp. 175-194). Sage.

Slater, M. D., \& Rouner, D. (2002). Entertainment-education and elaboration likelihood: Understanding the processing of narrative persuasion. Communication Theory, 12, 173-191.

Sood, S., Riley, A. H., \& Alarcon, K. C. (2017). Entertainment-education and health and risk messaging. In J. F. Nussbaum (Ed.), Oxford research encyclopedia of communication. https://doi.org/10.1093/acrefore/ 9780190228613.013.245 
Storey, D., \& Sood, S. (2013). Increasing equity, affirming the power of narrative and expanding dialogue: The evolution of entertainment education over two decades. Critical Arts, 27, 9-35.

Vaughan, P. W., Rogers, E. M., Singhal, A., \& Swalehe, R. M. (2000). Entertainment-education and HIV/AIDS prevention: A field experiment in Tanzania. Journal of Health Communication, 5, 81-100.

Wang, H., Choi, J. H., Wu, Y., \& DeMarle, A. (2018). BREAKAWAY: Combating violence against women and girls through soccer video game and youth camps. Health of New Media Research, 2(4), 159-184.

Wang, H., \& Singhal, A. (2009). Entertainment-education through digital games. In U. Ritterfeld, M. J. Cody, \& P. Vorderere (Eds.), Serious games: Mechanism and effects (pp. 271-292). Routledge.

Wang, H., \& Singhal, A. (2016). East Los High: Transmedia edutainment to promote the sexual and reproductive health of young Latina/o Americans. American Journal of Public Health, 106, 1002-1010. https://doi. org/10.2105/AJPH.2016.303072

Wang, H., \& Singhal, A. (2018). Audience-centered discourses in communication and social change: The "voicebook" of Main Kuch Bhi Kar Sakti Hoon, an entertainment-education initiative in India. Journal of Multicultural Discourses, 13, 176-191. https://doi.org/10.1080/17447143.2018.1481857

Wang, H., \& Singhal, A. (2021). Theorizing entertainment-education: A complementary perspective to the development of entertainment theory. In P. Vorderer \& C. Klimmt (Eds.), The Oxford handbook of entertainment theory (pp. 819-838). Oxford University Press.

Wang, H., Singhal, A., Quist, C., Sachdev, A., \& Liu, S. (2019). Aligning the stars in East Los High: How authentic characters and storylines can translate into real-life changes through transmedia edutainment. SEARCH Journal of Media and Communication Research, 11(3), 1-22.

Wang, H., Wu, Y., Choi, J. H., \& DeMarle, A. (2019). Players as transitional characters: How youth can “BREAKAWAY" from gender-based violence. Well Played, 8, 27-40. Retrieved from http://press.etc.cmu.edu/index.php/product/well-played-vol-8-no-1/

Wang, H., Xu, W., Saxton, G. D., \& Singhal, A. (2019). Social media fandom for health promotion? Insights from East Los High, a transmedia edutainment initiative. SEARCH Journal of Media and Communication Research, 11(1), 1-15.

Woolf, S. H. (2008). The meaning of translational research and why it matters. JAMA, 299, 211-213.

Yue, Z., Wang, H., \& Singhal, A. (2019). Using television drama as entertainmenteducation to tackle domestic violence in China. The Journal of Development Communication, 30(1), 30-44. 
Open Access This chapter is licensed under the terms of the Creative Commons Attribution-NonCommercial-NoDerivatives 4.0 International License (http:// creativecommons.org/licenses/by-nc-nd/4.0/), which permits any noncommercial use, sharing, distribution and reproduction in any medium or format, as long as you give appropriate credit to the original author(s) and the source, provide a link to the Creative Commons licence and indicate if you modified the licensed material. You do not have permission under this licence to share adapted material derived from this chapter or parts of it.

The images or other third party material in this chapter are included in the chapter's Creative Commons licence, unless indicated otherwise in a credit line to the material. If material is not included in the chapter's Creative Commons licence and your intended use is not permitted by statutory regulation or exceeds the permitted use, you will need to obtain permission directly from the copyright holder. 